\title{
Effect of Atorvastatin and Vitamin D on Freund's Adjuvant-Induced Rheumatoid Arthritis in Rat
}

\author{
Hendawy $\mathrm{OM}^{1 *}$, Ahmed WMS ${ }^{2}$, Abosaif AA $^{3}$, Mahmoud FA
}

${ }^{1}$ Department of Clinical Pharmacology, Faculty of Medicine, Beni-Suef University, Egypt

${ }^{2}$ Department of Clinical Pathology, Faculty of Veterinary Medicine, Beni-Suef University, Egypt

${ }^{3}$ Department of Clinical Pharmacology and Therapeutics, Faculty of Medicine, Al-Azhar University, Boys, Egypt

${ }^{4}$ Department of Medical Pharmacology, Faculty of Medicine, Cairo University, Egypt

\begin{abstract}
Rheumatoid arthritis (RA) is the most common chronic systemic, immune-mediated inflammatory disorderthat attacks flexible joints and also may affect many tissues and organs. The present study was designed to assess the effect of atorvastatin and vitamin D on RA and to compare it with that of methotrexate in female Wistar albino rats. Rheumatoid arthritis was induced by subcutaneousinjection of Complete Freund's Adjuvant (CFA). Seventy rats were divided into (7) groups, each of 10 rats. Group I was kept as control. Group II was injected with $0.4 \mathrm{ml}$ CFA for 12 days. Group III, IV and V were injected with CFA then treated with methotrexate, atorvastatin and vitamin D, respectively. Group VI and VII were injected with CFA then treated with atorvastatin plus methotrexate; vitamin $D$ plus methotrexate, respectively. Blood samples were collected after four weeks of the last dose of treatmentfor hematological examination. Serum samples were used for detection of inflammatory markers and lipid profile. A significantly increase of total leucocytes, neutrophils, lymphocytes, serum tumor necrosis factor $\alpha$ (TNF a), interleukine-6 (IL-6), total cholesterol (TC), triglycerides (TGs) and low density lipoprotein cholesterol (LDL) were observed in arthritis rats with significant decrease in high density lipoprotein cholesterol (HDL). Treatment with atorvastatin and vitamin D significantly decrease TNF $\alpha$, IL-6 and modulate the leukocytosis and lipid abnormalities comparable to that exerted by methotrexate. Thecombination therapy was even better than each drug alone and is promising for further clinical trials.
\end{abstract}

Keywords: Atorvastatin; Methotrexate; Rheumatic arthritis; Vitamin $\mathrm{D}$

\section{Introduction}

Rheumatoid arthritis (RA) is characterized by a chronic inflammation of synovium, leading to progressive joint destruction. Erosions of the peri-articular bone, the most specific hallmark of the disease, produce deformation, laxity, and functional disability. Although the cause of rheumatoid arthritis is unknown, autoimmunity plays an important role in both its chronicity and progression [1]. The pathogenesis of RA is not completely understood. Autoimmunity plays an important role in its pathogenesis.

Thelper 1 cells are assumed to play an important role in the initiation of RA. These cells may subsequently activate macrophages and other cell populations, including synovial fibroblasts. Macrophages and synovial fibroblasts are the main producers of the pro-inflammatory cytokines TNF- $\alpha$ and IL-1 [2].

Methotrexate is considered by many rheumatologists to be the most important and useful Disease-Modifying Anti-Rheumatic Drug [DMARDs] and is often part of the initial line of treatment. Methotrexate has shown to have toxic gastrointestinal, hematologic, pulmonary and hepatic adverse effects [3].

Central nervous system reactions to methotrexate have been reported, which includes myelopathies and leuco-encephalopathies. It has a variety of cutaneous side effects, particularly when administered in high doses [4].

Atorvastatin [statins], a lipid-lowering agent, decrease vascular risk in patients with coronary artery disease by lowering plasma levels of cholesterol [5].

Some of the clinical benefits of statin therapy may be independent of their cholesterol lowering effects. These so called pleiotropic effects are believed to include anti-inflammatory actions and immunosuppressive properties suggest a new face of statin therapy which makes them important not only in the treatment of dyslipidemias but also in chronic systemic inflammatory disease states through decreasing the secretion of pro-inflammatory cytokines [IL-6][6-8].

Vitamin D [calciferol] is a potent regulator of calcium homeostasis and may have immune-modulatory effects. Vitamin D has been shown to suppress the development of autoimmunity in some experimental animal models. Since vitamin D modulates the adaptive immune system, calciferol may have an important role in rheumatoid arthritis treatment [9-11].

The new trend of medical treatment of rheumatoid arthritis seeks for new drugs with more efficacy and less side effects since methotrexate, a standard diseased modified anti-rheumatoid drug, causes many adverse effects and toxicities including pulmonary, hepatic, renal and cardiac, we investigate the effects of vitamin D and atorvastatin as a combination therapy with methotrexatenot as a replacement therapy to overcome the adverse drug reactions caused by methotrexate.

*Corresponding author: Hendawy OM, Department of Clinical Pharmacology Faculty of Medicine, Beni-Suef University, Egypt, Tel: 01280182406; E-mail: omnia_mmh@yahoo.com

Received January 22, 2015; Accepted February 13, 2015; Published February 22, 2015

Citation: Hendawy OM, Ahmed WMS, Abosaif AA, Mahmoud FA (2015) Effect of Atorvastatin and Vitamin D on Freund's Adjuvant-Induced Rheumatoid Arthritis in Rat. J Bioequiv Availab 7: 090-094. doi:10.4172/jbb.1000221

Copyright: (C) 2015 Hendawy OM, et al. This is an open-access article distributed under the terms of the Creative Commons Attribution License, which permits unrestricted use, distribution, and reproduction in any medium, provided the original author and source are credited. 


\section{Material and Methods}

\section{Chemicals}

Methotrexate was obtained from Mylan SAS [USA]. Atorvastatin was purchased from Egyptian Int. Pharmaceutical Industries Co. E.I.P.I. Co.One-Alpha [Vitamin D] by Mina Pharm under license of Leo Pharmaceutical Product, Denmark. Complete Freund's adjuvant, Cell suspension [F5881] by Sigma-Aldrich, European Export.Each $\mathrm{mL}$ contains $1 \mathrm{mg}$ of Mycobacterium tuberculosis [H37Ra, ATCC 25177]; heat killed and dried, $0.85 \mathrm{~mL}$ paraffin oil and $0.15 \mathrm{~mL}$ mannidemonooleate.

Cholesterol, triglycerides, and high-density lipoproteinkits were obtained from Spin react Company [Spain]. All the other chemicals were of the highest analytical grade and purchased from Sigma-Aldrich Company.

\section{Animals and treatments}

Seventy adult female Wistar Albino rats, weighting 90-100 gwere obtained from the Egyptian Organization for Biological Products and Vaccine. They were housed 5 rats per cage with free access to commercial diet and tap water. The animals were handled according to guidelines of the local ethics committee, which comply with international laws for the use and care of laboratory animals. After one week of acclimatization, rats were randomly divided into seven equal groups of 10 rats each. The group I was kept as a control while group II was injected $0.4 \mathrm{ml}$ Complete Freund's Adjuvant subcutaneously in the right hind limb for 12 days divided in three doses [one dose every four days] to induce rheumatoid arthritis $[12,13]$.

The rats in groups III, IV, V, VI and VII were injected with complete Freund's Adjuvant as in group II to induce rheumatoid arthritis and then each group treated as follows: Group III was treated with methotrexate $0.2 \mathrm{mg} / 1 \mathrm{ml}$ intra-peritoneal once per week for four weeks after induction of arthritis [14]. Group IV was treated with atorvastatin $2 \mathrm{mg}$ /day orally for four weeks after induction of arthritis [13].

Group V was injected intra-peritoneal with Vitamin D $0.02 \mu \mathrm{g} /$ day for four weeks after induction of arthritis [15]. Group VI was treated with methotrexate and atorvastatin for four weeks after induction of arthritis. Group VII was treated with methotrexate and Vitamin D for four weeks after induction of arthritis.

\section{Collection and processing of samples}

After treatment was completed, blood samples were collected from orbital venous plexus under light anesthesia. Each sample was divided into two portions; the first was collected in clean dry Eppendorf tubes containing EDTA as anticoagulant to be used for hemogram studies. The second part was collected into non heparinized tubes which were centrifuged at $3000 \mathrm{rpm}$ for 10 minutes for separation of serum. The collected sera were stored at $-20^{\circ} \mathrm{C}$ for biochemical estimation.

\section{Complete blood count}

Total number of erythrocytes [RBCs], total number of leukocytes [WBCs], differential leukocyte count, platelet count, packed cell volume $[\mathrm{PCV}] \%$, and hemoglobin $[\mathrm{Hb}]$ concentration were estimated by adopting standard procedures. Blood smears were prepared as soon as possible after blood collection on a glass slide, quickly dried, and stained with Giemsa and May-Grunwald stain for the differential blood count. Erythrocyte indices like mean corpuscular volume [MCV], and mean corpuscular hemoglobin concentration $[\mathrm{MCHC}]$ were calculated according to standard formulas.

$$
\begin{aligned}
& \operatorname{MCV}[\mathrm{fl}]=\mathrm{PCV} / \mathrm{RBC} \text { count } \times 10 \\
& \mathrm{MCHC}[\mathrm{g} / \mathrm{dl}]=\mathrm{Hb} / \mathrm{PCV} \times 100 .
\end{aligned}
$$

\section{Biochemical parameters}

Tumor necrosis factor $\boldsymbol{\alpha}$ [TNF $\boldsymbol{\alpha}]$ : Tumor necrosis factor $\alpha$ was determined by in vitro Enzyme Linked Immunosorbent Assay [ELISA] kit, using colourimetric reaction method as instructed in the kit manual [16]. to [17]

Serum interleukin 6 [IL 6]: IL6 was determined in serum according

Lipid profile: The serum lipid contents were assayed using enzyme-based kits. Serum triglycerides [TG] were estimated according to [18]. The serum total cholesterol level was estimated according to the method as described by [19].

High-density lipoprotein-cholesterol [HDL-C] was estimated by precipitation with phosphotungstic acid and magnesium chloride according to the method described by [20].

The concentration of serum low-density lipoprotein [LDL] was calculated with the Friedewald formula [21]. /5]

LDL $[\mathrm{mg} / \mathrm{dl}]=$ Total cholesterol - HDL cholesterol-[triglycerides

\section{Statistical analysis}

Statistical analysis was carried out using Graph Pad Prism 5 [Graph Pad Software, San Diego, CA, USA]. Groups of data were compared with an analysis of variance [one-way ANOVA] followed by Tukey's multiple comparison test. Values of $\mathrm{P}<0.05$ were regarded as significant. Results are expressed as mean \pm S.E.M.

\section{Results}

Data presented in Table 1 shows the values of hemogram in different groups. Erythrocyte count, PCV \%, hemoglobin content, $\mathrm{MCV}$ and MCHC were insignificantly changed in the arthritis group that received vehicle, atorvastatin, and methotrexate plus atorvastatin groups when compared with the control group. Only methotrexate treated group shows a significant decrease of $\mathrm{Hb}$ conc.and $\mathrm{MCHC} \%$ when compared to control group.

The blood leucocytic count was significantly increased in the adjuvant group compared with the control group with concomitant increases in neutrophils and lymphocytes count. In methotrexate group, significant decrease of total leucocytes, accompanied by neutrophilia, and lymphocytosis was observed when compared with the control and adjuvant groups. Atorvastatin group showed normal leucocytic count with neutrophilia when compared with control group and lymphopenia when compared with adjuvant group. Combination of methotrexate and atorvastatin resulted in significant decrease of leucocytic count with lymphopenia when compared with the control group.

Table 2 showed that in adjuvant group, serum levels of TNF and IL6 were significantly increase compared to the control. While, treatment with methotrexate, atorvastatin, and methotrexate plus atorvastatin resulted in significant decrease of TNF and IL6 levels when compared to adjuvant group and their values reverted to normal except 


\begin{tabular}{|c|c|c|c|c|c|c|c|}
\hline & Control & Adjuvant & MTX & ATR & Vit D & $\begin{array}{c}\text { MTX+ } \\
\text { ATR }\end{array}$ & $\begin{array}{l}\text { MTX+ } \\
\text { Vit D }\end{array}$ \\
\hline RBCs $\left(10^{6} / \mu \mathrm{l}\right)$ & $6.88 \pm 0.24$ & $7.35 \pm 0.19$ & $6.15 \pm 0.09$ & $6.46 \pm 0.12$ & $7.12 \pm 0.32$ & $6.48 \pm 0.08$ & $6.79 \pm 0.30$ \\
\hline $\mathrm{Hb}(\mathrm{g} / \mathrm{dl})$ & $14.13 \pm 0.74$ & $14.37 \pm 0.36$ & $12.08^{a} \pm 0.35$ & $13.05 \pm 0.36$ & $14.70 \pm 0.82$ & $12.83 \pm 0.32$ & $13.50 \pm 0.76$ \\
\hline PCV (\%) & $41.17 \pm 1.49$ & $42.00 \pm 0.84$ & $38.33 \pm 0.49$ & $39.00 \pm 0.57$ & $43.17 \pm 1.97$ & $38.00 \pm 0.63$ & $41.67 \pm 1.16$ \\
\hline $\operatorname{MCV}$ (fl) & $59.94 \pm 0.11$ & $59.95 \pm 0.08$ & $58.84 \pm 0.47$ & $60.33 \pm 0.28$ & $60.33 \pm 1.11$ & $58.79 \pm 0.41$ & $60.11 \pm 0.45$ \\
\hline MCHC (\%) & $34.11 \pm 0.59$ & $34.29 \pm 0.17$ & $31.83^{a} \pm 0.57$ & $33.43 \pm 0.52$ & $33.96 \pm 0.62$ & $33.85 \pm 0.25$ & $33.89 \pm 0.36$ \\
\hline WBCs $\left(10^{3} / \mu \mathrm{l}\right)$ & $8.53 \pm 0.45$ & $12.05^{a} \pm 1.06$ & $5.21^{\mathrm{a}, \mathrm{b}} \pm 0.23$ & $10.79 \pm 1.06$ & $9.50 \pm 0.60$ & $4.61^{\mathrm{a}, \mathrm{b}} \pm 0.40$ & $4.30^{\mathrm{a}, \mathrm{b}} \pm 0.47$ \\
\hline Neut $\left(10^{3} / \mu \mathrm{l}\right)$ & $2.73 \pm 0.12$ & $4.70^{\mathrm{a}} \pm 0.44$ & $1.69^{a, b} \pm 0.03$ & $4.29 a \pm 0.19$ & $4.07^{a} \pm 0.25$ & $2.57^{b} \pm 0.03$ & $1.64^{\mathrm{a}, \mathrm{b}} \pm 0.03$ \\
\hline Lymph $\left(10^{3} / \mu \mathrm{l}\right)$ & $5.35 \pm 0.29$ & $7.11^{a} \pm 0.01$ & $3.51^{\mathrm{a}, \mathrm{b}} \pm 0.20$ & $6.10 \pm 0.21$ & $5.01^{b} \pm 0.46$ & $1.84^{\mathrm{a}, \mathrm{b}} \pm 0.07$ & $2.28^{\mathrm{a}, \mathrm{b}} \pm 0.31$ \\
\hline Mono $\left(10^{3} / \mu \mathrm{l}\right)$ & $0.14 \pm 0.01$ & $0.19 \pm 0.03$ & $0.12 \pm 0.01$ & $0.15 \pm 0.03$ & $0.19 \pm 0.02$ & $0.03^{\mathrm{a}, \mathrm{b}} \pm 0.00$ & $0.19 \pm 0.15$ \\
\hline Eosino $\left(10^{3} / \mu \mathrm{l}\right)$ & $0.17 \pm 0.01$ & $0.11 \pm 0.02$ & $0.05^{a, b} \pm 0.01$ & $0.16 \pm 0.01$ & $0.17 \pm 0.02$ & $0.04^{\mathrm{a}, \mathrm{b}} \pm 0.00$ & $0.16 \pm 0.10$ \\
\hline
\end{tabular}

Letter a- indicates significant variation in comparison with control group.

Letter b- indicates significant variation in comparison with adjuvant group.

$\mathrm{RBCs}=$ Red blood count; $\mathrm{Hb}=$ hemoglobin; $\mathrm{PCV}=$ packed cell volume; $\mathrm{MCV}=$ mean corpuscular volume; $\mathrm{MCHC}=$ mean corpuscular hemoglobin concentration; WBCs= white blood cell count; Neut= neutrophil; Lymph=lymphocyte; Mono= monocyte and Eosino= eosinophils

Table 1: Hematological values (mean \pm SE) from different rats groups.

\begin{tabular}{|c|c|c|c|c|c|c|c|}
\hline & Control & Adjuvant & MTX & ATR & Vit D & MTX+ATR & MTX+ Vit D \\
\hline TNFa & $28.27 \pm 1.0$ & $64.9^{\mathrm{a}} \pm 4.5$ & $39.19^{b} \pm 2.6$ & $36.19^{b} \pm 2.4$ & $34.84^{b} \pm 1.8$ & $31.76^{b} \pm 1.0$ & $41.8^{\mathrm{a}, \mathrm{b}} \pm 2.2$ \\
\hline IL-6 & $29.13 \pm 2.2$ & $67.26^{a} \pm 4.1$ & $42.54^{b} \pm 2.4$ & $36.03^{b} \pm 2.5$ & $35.77^{b} \pm 2.9$ & $31.74^{b} \pm 1.8$ & $40.70^{\mathrm{a}, \mathrm{b}} \pm 1.6$ \\
\hline TGs & $48.61 \pm 1.2$ & $77.6^{\mathrm{a}} \pm 4.2$ & $58.33^{b} \pm 2.0$ & $52.27^{b} \pm 1.8^{\#}$ & $54.5^{b} \pm 2.3$ & $52.56^{b} \pm 2.2$ & $52.9^{b} \pm 2.0$ \\
\hline TC & $112.8 \pm 4.9$ & $159^{\mathrm{a}} \pm 6.2$ & $137.8^{a, b} \pm 4.7$ & $130.1^{b} \pm 1.1$ & $127.1^{b} \pm 2.7$ & $124.3^{b} \pm 1.8$ & $127.2^{b} \pm 2.2$ \\
\hline HDL & $49.89 \pm 1.5$ & $37.46^{a} \pm 2.0$ & $43.7 \pm 2.50$ & $38.94^{a} \pm 1.7$ & $42.44 \pm 1.4$ & $34.56^{a} \pm 0.9$ & $40.79^{b} \pm 1.8$ \\
\hline LDL & $53.17 \pm 3.7$ & $106.1^{\mathrm{a}} \pm 7.1$ & $82.42^{\mathrm{a}, \mathrm{b}} \pm 6.8$ & $80.6^{b} \pm 1.7$ & $73.74^{b} \pm 2.9$ & $79.26^{\mathrm{a}, \mathrm{b}} \pm 1.5$ & $75.77^{\mathrm{a}, \mathrm{b}} \pm 2.9$ \\
\hline
\end{tabular}

Letter a- indicates significant variation in comparison with control group.

Letter $b$ - indicates significant variation in comparison with adjuvant group.

TNF $\alpha=$ tumor necrosis factor $\alpha ; \mathrm{IL}-6=$ interleukine- 6 ; TC= total cholesterol; TGs= triglycerides; HDL= high density lipoprotein cholesterol and LDL= low density lipoprotein cholesterol.

Table 2: Biochemical results (mean $\pm S E$ ) from different rats groups

in methotrexate group, the IL6 level is still significantly higher than control.

Serum total cholesterol, TGs, and LDL cholesterol were significantly increased, while HDL- cholesterol was significantly decreased in adjuvant group when compared with the control. In methotrexate group, triglycerides and HDL-cholesterol values were insignificant changed, while cholesterol and LDL values were significantly increasewhen compared to control group. Values of TGs and cholesterol were reverted to normal levels, while HDL level was significantly decreased and LDL level was increased in atorvastatin and methotrexate plus atorvastatin groups when compared with the control.

\section{Discussion}

The new trend of medical treatment of rheumatoid arthritis seeks for new drugs with more efficacy and less side effects [22] since methotrexate causes many toxicities include hepatic fibrosis, pulmonary fibrosis renal insufficiency and cardiovascular diseases [23] further more RA and atherosclerosis may share several common pathomechanisms and inflammation undoubtedly plays a primary role [24].

RA-related inflammation may lead to atherosclerosis occurrence through enhancement of oxidative modification of LDL and stimulation of superoxide \& dismutase secretion from monocytes and endothelial cells [25].

Anti-inflammatory effect of statins therapy is to reverse endothelial dysfunction by prevention of LDL oxidation and increasing nitric oxide bioavailability [26] also the biologically active form of vitamin D [calcitriol] in the immune system acts locally as a cytokine, defending the body against microbial invaders [27]. So that statins and vitamin D may have an important role in treatment of RA.

In this study, the hematological results showed that induction of rheumatoid arthritis caused a significant leukocytosis accompanied with neutrophilia due to stimulation of the immune response to help the body to fight infection by producing antibodies that circulate widely in the blood stream, recognizing the foreign particles and triggering inflammation [28]. Treatment with methotrexate resulted in decreased hemoglobin level, leucopenia accompanied with neutrophilia, lymphopenia and eosinopenia, Omoigui et al.[29] mentioned that patients on methotrexate require careful monitoring of hemoglobin and complete blood count, two weeks after initiation of treatment.

While atorvastatin either vitamin D didn't affect the high level of neutrophil. On the other hand, combination therapy leads to reduce the level of neutrophil in comparison with diseased group confirming that these combinations have synergistic effects.

In the present study, the induction of RA [adjuvant group] resulted in elevated values of TNF $\alpha$ and IL-6. This may be due to stimulation of cell mediated immunity that leads to the potentiation of the production of certain immuno-globulins by FCA causing RA $[22,30]$.

Methotrexate treatment caused a significant decrease in TNFa and IL- 6 levels. methotrexate is considered a folate analogue that inhibit dihydrofolate reductase [31] involved in the de novo synthetic pathways for purine and pyrimidine precursors of DNA and RNA required for cell proliferation. Methotrexate treatment also reduces the production of pro-inflammatory cytokines such as IL-1, IL-2, IL-6 and interferon [INF] $-\gamma$ and suppresses TNF activity [29]. 
Treatment of arthritis rats with atorvastatin resulted in reduction of inflammation by reduction of CRP and lowers the level of tumor necrosis factor even more than the decrease recorded with methotrexate [32].

In vitamin $\mathrm{D}$ treated group, the results showed a decrease in the level of TNFa and IL-6 relatively as vitamin D may reduce expression of Prostaglandins ES and increase expression of Prostaglandins DS by antigen presenting cells called dendritic cells from synovium rich tissue [33].

Combination of atorvastatin with methotrexate in group VI recorded a statistically significant decrease in the level of TNFa and IL-6 in comparison with RA group. This decrease was more than that recorded with each drug alone while combination of vitamin $\mathrm{D}$ with methotrexate wasn't effective as each drug alone.

In the current study, a significant increase in the levels of triglycerides, cholesterol and LDL were recorded in adjuvant group. This may be occurred due to enhancement of oxidative modification of LDL and stimulation of superoxide dismutase secretion from monocytes and endothelial cells [25]. In addition, a significant decrease in HDL level was observed, this may be due to Paraoxnase activity reduction [25]. The decrease in HDL will lead to lose their ability to remove cholesterol from atherosclerotic lesions and reducing their antioxidant activity [34].

Treatment of arthritis rats with methotrexate leads to decrease the elevated levels of TGs, LDL and cholesterol when compared with the adjuvant group, however, cholesterol and LDL levels failed to return to normal when compared with control group. On the other hand, atorvastatin treatment improves the lipid abnormalities caused by RA as the values of TGs and TC were return to normal while the HDL and LDL were significantly improved when compared with adjuvant group but still significantly than normal.

Kremer and Phelps, Choi et al. [35,36] reported that MTX treatment exhibits a substantial survival benefit, mainly by reducing cardiovascular mortality while treatment with atorvastatin reduced the level of TGs, TC and LDL even better than that caused by methotrexate comparing with rheumatoid arthritis group due to inhibition of intracellular isoprenoids formation, suppression of vascular and myocardial inflammation, favorably modulate vascular and myocardial redox state and improve nitric oxide bioavailability [37]. Statins block the pathway for synthesizing cholesterol in the liver [38] while vitamin D supplementation could increase LDL concentrations, but does not appear to significantly affect total cholesterol, HDL and triglycerides [39].

It was also stated by Kabel et al. [40] that the combination of MTX and atorvastatin had a better effect than each of MTX or atorvastatin alone against tissue glutathione reductase, catalase, malondial dehyde, cholesterol and tumor necrosis factor alpha in solid Ehrlich tumor in mice.

In the present study, administration of vitamin $\mathrm{D}$ plus methotrexate resulted in significant decrease of the level of LDL less than that decrease caused by vitamin $\mathrm{D}$ alone or with methotrexate alone compared with RA group while the significant decrease in TGs level was more than that caused by vitamin D alone. Our results also recorded that the decrease in level of cholesterol caused by treatment with vitamin $\mathrm{D}$ and methotrexate was statistically significant and relatively similar to which caused by vitamin $\mathrm{D}$ alone on the other hand there was a significant decrease in level of HDL.

\section{Conclusion}

From the current study, we can concluded that atorvastatin and vitamin D showed a powerful anti-rheumatoid effect against Freund's Complete Adjuvant induced rheumatoid arthritis in rats comparable to that exerted by DMARDs such as methotrexate. Combination therapy was even more effective with less adverse effects than each drug alone for further clinical trial.

\section{References}

1. Majithia V, Geraci SA (2007) Rheumatoid arthritis: diagnosis and management Am J Med 120: 936-939.

2. Pavkova Goldbergova M, Pavek N, Lipkova J, Jarkovsky J, Stouracova M, et al (2012) Circulating cytokine pattern and factors describing rheumatoid arthritis: IL-15 as one of the biomarkers for RA? Biomarkers 17: 655-662.

3. Wasserman AM (2011) Diagnosis and management of rheumatoid arthritis. Am Fam Physician 84: 1245-1252.

4. Scheinfeld N (2006) Three cases of toxic skin eruptions associated with methotrexate and a compilation of methotrexate-induced skin eruptions. Dermatol Online J 12: 15.

5. Shepherd J, Hunnighake DB, Barter P, Mckenney JM, Hutchinson HG (2003) Guidelines for lowering lipids to reduce coronary artery disease risk: A comparison of rosuvastatin with atorvastatin, pravastatin and simvastatin for achieving lipid lowering goals. Am J Cardiol 91: 11C-19C.

6. McCarey DW, Mclnnes IB, Madhok R, Hampson R, Scherbakov O, et al. (2004) Trial of Atorvastatin in Rheumatoid Arthritis (TARA): double-blind, randomised placebo-controlled trial. Lancet 363: 2015-2021.

7. Tandon V, Bano G, Khajuria V, Parihar A, Gupta S (2005) Pleiotropic effects of statins. Indian J Pharmacol 37: 77-85

8. El-Barbary AM, Hussein MS, Rageh EM, Hamouda HE, Wagih AA, et al. (2011) Effect of atorvastatin on inflammation and modification of vascular risk factors in rheumatoid arthritis. J Rheumatol 38: 229-235.

9. Merlino LA, Curtis J, Mikuls TR, Cerhan JR, Criswell LA, et al. (2004) Vitamin $D$ intake is inversely associated with rheumatoid arthritis: results from the lowa Women's Health Study. Arthritis Rheum 50: 72-77.

10. Baker JF, Baker DG, Toedter G, Shults J, Von Feldt JM, et al. (2012) Associations between vitamin D, disease activity, and clinical response to therapy in rheumatoid arthritis. Clin Exp Rheumatol 30: 658-664.

11. Haque UJ, Bathon JM, Giles JT (2012) Association of vitamin D with cardiometabolic risk factors in rheumatoid arthritis. Arthritis Care Res (Hoboken) 64: 1497-1504.

12. Tatsuo MA, Carvalho WM, Silva CV, Miranda AE, Ferreira SH, et al. (1994) Analgesic and antiinflammatory effects of dipyrone in rat adjuvant arthritis model. Inflammation 18: 399-405.

13. Franklin J, Lunt M, Bunn D, Symmons D, Silman A (2006) Incidence of lymphoma in a large primary care derived cohort of cases of inflammatory polyarthritis. Ann Rheum Dis 65: 617-622.

14. Kuroda M, Kobayashi Y, Tanaka Y, Itani T, Mifuji R, et al. (2004) Increased hepatic and renal expressions of multidrug resistance-associated protein 3 in Eisai hyperbilirubinuria rats. J Gastroenterol Hepatol 19: 146-153.

15. Johnsson C, Binderup L, Tufveson G (1996) Immunosuppression with the vitamin D analogue MC 1288 in experimental transplantation. Transplant Proc 28: 888-891.

16. Barbuio R, Milanski M, Bertolo MB, Saad MJ, Velloso LA (2007) Infliximab reverses steatosis and improves insulin signal transduction in liver of rats fed a high-fat diet. J Endocrinol 194: 539-550.

17. MuÃ $\pm 0 z$ S, HernÃjndez-Pando R, Abraham SN, Enciso JA (2003) Mast cell activation by Mycobacterium tuberculosis: mediator release and role of CD48. J Immunol 170: 5590-5596.

18. Bucolo G, David H (1973) Quantitative determination of serum triglycerides by the use of enzymes. Clin Chem 19: 476-482.

19. Naito HK (1984a) Cholesterol. In: Kaplan LA, Pesce AJ (Edn). Clinical chemistry: theory, analysis and correlation. St. Louis: CV. Mosby Co 437:11941206. 
Citation: Hendawy OM, Ahmed WMS, Abosaif AA, Mahmoud FA (2015) Effect of Atorvastatin and Vitamin D on Freund's Adjuvant-Induced Rheumatoid Arthritis in Rat. J Bioequiv Availab 7: 090-094. doi:10.4172/jbb.1000221

20. Naito HK (1984b) High-density lipoprotein(HDL) cholesterol. In: Kaplan A, et al. Clin Chem. The CV Mosby Co St Louis, Toronto Princeton 437:1207-1213.

21. Friedewald WT, Levy RI, Fredrickson DS (1972) Estimation of the concentration of low-density lipoprotein cholesterol in plasma, without use of the preparative ultracentrifuge. Clin Chem 18: 499-502.

22. Westwood OM, Nelson PN, Hay FC (2006) Rheumatoid factors: what's new? Rheumatology (Oxford) 45: 379-385.

23. Baggott JE, Morgan SL, Ha TS, Alarc $\tilde{A}^{3} n$ GS, Koopman WJ, et al. (1993) Antifolates in rheumatoid arthritis: a hypothetical mechanism of action. Clin Exp Rheumatol 11 Suppl 8: S101-105.

24. Meune C, TouzÃ@ E, Trinquart L, Allanore Y (2009) Trends in cardiovascular mortality in patients with rheumatoid arthritis over 50 years: a systematic review and meta-analysis of cohort studies. Rheumatology (Oxford) 48: 1309-1313.

25. Ku IA, Imboden JB, Hsue PY, Ganz P (2009) Rheumatoid arthritis: model of systemic inflammation driving atherosclerosis. Circ J 73: 977-985.

26. Parker RA, Huang Q, Tesfamariam B (2003) Influence of 3-hydroxy-3methylglutaryl-CoA (HMG-CoA) reductase inhibitors on endothelial nitric oxide synthase and the formation of oxidants in the vasculature. Atherosclerosis 169: 19-29.

27. Adams JS, Hewison M (2010) Update in vitamin D. J Clin Endocrinol Metab 95: 471-478.

28. Anderson J, Caplan L, Yazdany J, Robbins ML, Neogi T, et al. (2012) Rheumatoid arthritis disease activity measures: American College of Rheumatology recommendations for use in clinical practice. Arthritis Care Res 64: $640-647$.

29. Omoigui S, Fadare A, Ogbechie C (2014) Relief and Resolution of Fibromyalgia Symptoms with Low Dose Methotrexate - The Origin of Pain are Inflammation and the Inflammatory Response. Rheumatology 4:129-131.

30. Sattar N, McCarey DW, Capell H, Mclnnes IB (2003) Explaining how "high- grade" systemic inflammation accelerates vascular risk in rheumatoid arthritis. Circulation 108: 2957-2963.

31. Seeger DR, Cosalich DB, Smith JM, Hultquist ME (1949) Analogs of pteroylglutamic acid. III. 4-amino derivatives. J Am Chem Soc 71: 1297-1301.

32. Bu DX, Griffin G, Lichtman AH (2011) Mechanisms for the anti-inflammatory effects of statins. Curr Opin Lipidol 22: 165-170.

33. Moghaddami M, Mayrhofer G, Anderson PH, Morris HA, Van Der Hoek M et al. (2012) Efficacy and mechanisms of action of vitamin D in experimental polyarthritis. Immunol Cell Biol 90: 168-177.

34. Van Lenten BJ, Reddy ST, Navab M, Fogelman AM (2006) Understanding changes in high density lipoproteins during the acute phase response. Arterioscler Thromb Vasc Biol 26: 1687-1688.

35. Kremer JM, Phelps CT (1992) Long-term prospective study of the use of methotrexate in the treatment of rheumatoid arthritis. Update after a mean of 90 months. Arthritis Rheum 35: 138-145.

36. Choi HK, HernÃ in MA, Seeger JD, Robins JM, Wolfe F (2002) Methotrexate and mortality in patients with rheumatoid arthritis: a prospective study. Lancet 359: 1173-1177.

37. Antonopoulos AS, Margaritis M, Lee R, Channon K, Antoniades C (2012) Statins as anti-inflammatory agents in atherogenesis: molecular mechanisms and lessons from the recent clinical trials. Curr Pharm Des 18: 1519-1530.

38. Miettinen TA (1982) Diurnal variation of cholesterol precursors squalene and methyl sterols in human plasma lipoproteins. J Lipid Res 23: 466-473.

39. Jorde R, Grimnes G (2011) Vitamin D and metabolic health with specia reference to the effect of vitamin D on serum lipids. Prog Lipid Res 50: 303-312.

40. Kabel AM, Abdel-Rahman MN, El-Sisi Ael-D, Haleem MS, Ezzat NM, et al. (2013) Effect of atorvastatin and methotrexate on solid Ehrlich tumor. Eur J Pharmacol 713: 47-53. 